\title{
Cardioprotective Effects of Resistance Training on Obesity
}

\author{
Marcelo Diarcadia Mariano Cezar, ${ }^{1 \oplus}$ Luana Urbano Pagan, ${ }^{2 \oplus}$ Ricardo Luiz Damatto, ${ }^{1 \oplus}$ Aline Lima, ${ }^{2}$ \\ Mariana Janini Gomes ${ }^{2}$ \\ Faculdade de Ciências Sociais e Agrárias de Itapeva (FAIT), ${ }^{1}$ Itapeva, SP - Brazil \\ Faculdade de Medicina de Botucatu, Universidade Estadual Paulista (UNESP), ${ }^{2}$ Botucatu, SP - Brazil \\ Short Editorial related to the article: Resistance Exercise Modulates Oxidative Stress Parameters and TNF- $\alpha$ Content in the Heart of Mice with \\ Diet-Induced Obesity
}

Obesity is characterized as a complex metabolic disorder and is associated with several complications such as cardiovascular diseases, diabetes, renal dysfunction, liver dysfunction and cancer, resulting in impairment of quality of life. ${ }^{1}$

The pathogenesis of obesity has a multifactorial origin and the oxidative stress may play an important role. Studies on animals and cell culture have reported how oxidative stress can contribute to the development of obesity, causing increased preadipocytes proliferation, adipocyte differentiation, and size of mature adipocytes, resulting in increased production of pro-inflammatory cytokines such as tumor necrosis factor alpha $(\mathrm{TNF}-\alpha)^{2,3}$

Experimental model of high fat diet-induced obesity aims to reproduce the characteristics observed in human, such as the development of cardiovascular abnormalities. ${ }^{4,5}$ The study

\section{Keywords}

Obesity/complications; Cardiovascular Diseases/mortality; Diabetes Mellitus; Hypertension; Mice; Diet, High-fat; Exercise; Quality of Life.

Mailing Address: Marcelo Diarcadia Mariano Cezar •

Faculdade de Ciências Sociais e Agrárias de Itapeva (FAIT) - Rodovia

Francisco Alves Negrão, km 285 Itapeva, SP - Brazil

E-mail: marcelocezar@fait.edu.br

DOI: $10.5935 / a b c .20190085$ of Effting et al. ${ }^{6}$ evaluated the effects of resistance training on parameters of oxidative stress and inflammation in mice with high fat diet-induced obesity.

Currently, regular physical exercise has been recommended for the treatment of obesity. Exercise practicing results in numerous health benefits, such as improvement in body composition, physical capacity, insulin resistance, endothelial function, arterial hypertension, antioxidant status and quality of life. ${ }^{7,8}$

Data presented by the authors of the article "Resistance Exercise Modulates Oxidative Stress Parameters and TNF- $\alpha$ Content in the Heart of Mice with Diet-Induced Obesity" showed important cardioprotective effects of resistance training, which resulted in decreased levels of lipid peroxidation and reactive oxygen species, modulation of antioxidant enzymes activity and a decrease in myocardial TNF- $\alpha$ concentration of obese mice ${ }^{6}$. Similarly, Alves et al. ${ }^{9}$ observed that eight weeks of resistance exercise was associated with an improvement on inflammatory profile in the heart of rats with myocardial infarction.

The effects of resistance exercise on oxidative stress have been investigated mainly in skeletal muscle. ${ }^{10-12}$ There are few studies evaluating the effects of resistance exercise on the redox status of the cardiac muscle in the literature. Therefore, Effting et al. ${ }^{6}$ presented relevant data supporting resistance exercise as a therapeutic approach to obesity, being able to prevent or mitigate metabolic changes and improve the quality of life.

\section{References}

1. Manna P, Jain SK. Obesity, oxidative stress, adipose tissue dysfunction, and the associated health risks: causes and therapeutic strategies. Metab Syndr Relat Disord. 2015;13(10):423-44.

2. Furukawa S, Fujita T, Shimabukuro M, Iwaki M, Yamada Y, Nakajima Y, et al. Increased oxidative stress in obesity and its impact on metabolic syndrome. J Clin Invest. 2004;114(12):1752-61.

3. Higuchi M, Dusting GJ, Peshavariya H, Jiang F, Hsiao ST, Chan EC, et al. Differentiation of human adipose-derived stem cells into fat involves reactive oxygen species and Forkhead box $\mathrm{O} 1$ mediated upregulation of antioxidant enzymes. Stem Cells Dev. 2013;22(6):878-888.

4. Nascimento TB, Baptista RF, Pereira PC, Campos DH, Leopoldo AS, Leopoldo AP, et al. Vascular alterations in high-fat diet-obese rats: role of endothelial L-arginine/NO pathway. Arq Bras Cardiol. 2011;97(1):40-5.

5. Martins F, Campos DHS, Pagan LU, Martinez PF, Okoshi K, Okoshi MP, et al. High-fat diet promotes cardiac remodeling in an experimental model of obesity. Arq Bras Cardiol. 2015;105(5):479-486.

6. Effting PS, Brescianini SMS, Sorato HR, Fernandes BB, Fidelis GSP, Silva PRL, et al. Resistance exercise modulates oxidative stress parameters and TNF- $\alpha$ content in the heart of mice with obesity induced by a high-fat diet. Arq Bras Cardiol. 2019; 112(5):545-552. 
7. Gomes MJ, Martinez PF, Pagan LU, Damatto RL, Cezar MDM, Lima ARR, et al. Skeletal muscle aging: influence of oxidative stress and physical exercise. Oncotarget. 2017;8(12):20428-40.

8. Pagan LU, Gomes MJ, Okoshi MP. Endothelial function and physical exercise. Arq Bras Cardiol. 2018;111(4):540-1.

9. Alves JP, Nunes RB, Stefani GP, Dal Lago P. Resistance training improves hemodynamic function, collagen deposition and inflammatory profiles: experimental model of heart failure. PLoS One. 2014;9(10):e110317.

10. Scheffer DL, Silva LA, Tromm CB, da Rosa GL, Silveira PC, de Souza CT, et al. Impact of different resistance training protocols on muscular oxidative stress parameters. Appl Physiol Nutr Metab. 2012;37(6):1239-46.

11. Cai M, Wang Q, Liu Z, Jia D, Feng R, Tian Z. Effects of different types of exercise on skeletal muscle atrophy, antioxidant capacity and growth factors expression following myocardial infarction. Life Sci. 2018;213:40-9.

12. Vilela TC, Effting PS, Dos Santos PG, Farias H, Paganini L, Rebelo SH, et al. Aerobic and strength training induce changes in oxidative stress parameters and elicit modifications of various cellular components in skeletal muscle of aged rats. Exp Gerontol. 2018;106:21-7. 